\title{
Determining Prevelance of Mastitis Cases among the Cows in Kutahya and Isolation and Identification of S.aureus and E.coli Strains Which Are Two Causes of Mastitis
}

\author{
Aysel Gulbandilar (Corresponding author) \\ Eskisehir Osmangazi University, Faculty of Agriculture, \\ Department of Food Engineering. Ali Numan Kirac Campus, Eskisehir, Turkey \\ E-mail: aysel.gulbandilar@ogu.edu.tr \\ Mehtap Okur \\ Altintas Vocational School, Dumlupinar University, Altintas-Kutahya, Turkey \\ E-mailmehtap.okur@dpu.edu.tr \\ Kiymet Guven \\ Eskisehir Technical University, Faculty of Science, \\ Department of Biology, Eskisehir, Turkey \\ E-mail kguven@eskisehir.edu.tr
}

\begin{abstract}
In this project, the prevalence of mastitis cases, isolation, identification and antimicrobial susceptibilities of $S$. aureus and $E$. coli causing mastitis were aimed in the center and districts of the province of Kutahya. Different races of 350 cows were milked at different lactation periods and 111 milk samples $(31.71 \%)$ inspected by California Mastitis Test (CMT) were recorded as positive. $S$. aureus were isolated from 60 milk samples whereas $E$. coli were isolated from 51 samples. Identification was carried out by traditional biochemical tests. Antimicrobial susceptibility tests showed that 45 out of 60 isolates (75\%) in S. aureus and 51 out of 43 (84.31) isolates in E.coli were resistant to penicillin. Erythromycin, amoxicillin-clavulanic acid, gentamycin resistance were also determined for $S$. aureus and $E$. coli isolates. The study provides valuable information about the measures to be taken and treatment methods that can be applied against mastitis-borne infections contributing to take precautions against the economic losses caused by mastitis in Kutahya.
\end{abstract}

Key Words: Mastitis, Cow, E.coli, S. aureus, antibiotic susceptibility test.

DOI: $10.7176 / \mathrm{JSTR} / 5-10-08$

\begin{abstract}
1. Introduction
Wellbeing and high quality of milk, that plays an important role in human nutrition, is closely related with udders where it is produced. In Turkey, just like many other countries, a large and dynamic section of farming economy is dairy industry, which most frequently faces with the problem of "Mastitis". Mastitis is usually defined as inflammatory disorders observed in milk producing tissue of udders, ducts and all milk storage parts of the animal's body (Albenzio et al., 2002) and (Albayrak, 2007). The causes of mastitis are classified under three main groups: those depending on the cow, caring and environmental factors and milking process. The factors depending on the cow itself can be listed as race and heritage, age and number of lactation, udder form, milk productivity, lactation period, strength of the immunity system, lesions on the udders and nipples and finally ease of milking. Caring and environmental factors are microorganisms, the environment, the cow house organization and conditions, the ground and the base, tethering style, nutrition, exercise and seasonal effects. The milking process stands for factors such as excitation before milking, milking hygiene and technique, the problems of the milking machine and experience of the person who milks the cows. The disease causes milk productivity loss, changes in the combination of the milk, and a decrease in the productive live spans of the cows (Albenzio et al., 2002).
\end{abstract}


Mastitis which is seen among dairy cattle constitutes a big problem for cattle raisers. As a matter of fact, all around the world dairy cattle businesses have been experiencing losses costing millions of dollars due to mastitis. Therefore, any case of mastitis should be detected among the herd immediately and necessary precautions should be taken. One of the main reasons for the importance of mastitis is that the subclinical form of the disease is 20 to 30 times more frequent than its clinical form. As subclinical mastitis cases are not easily detected by the raisers, it can continue its existence on the animal for a long time. Moreover, both clinical and subclinical mastitis are cured quite difficultly. There is a large number of cases which resist treatment and repeat several times. Besides the destruction on the udders resulting from the disease is usually irrevocable. Therefore, many researches concerningff treatment, eradication and protection from this disease have been performed so far. However, it was never possible to eradicate this disease totally as too many factors play important roles in etiology of mastitis. In this context the main aim has been minimizing the destruction caused by the disease (Baştan, 2010).

Many factors have been isolated and identified from mastitis cases. Bacteria constitute a considerable part of these factors. In mastitis cases among cows Staphylococcus aureus (S.aureus) and Escherichia coli $(E$. coli) microorganisms were reported to have significant incidence and the most frequently observed bacteria was $E$. coli followed by S.aureus. Today various methods are used for identification of these bacteria. The ideal system is considered to be easy, fast, realistic, highly differential and repeatable (Bergonier and Bertholet, 2003) and (Alaçam et al, 1986) and (Sumathi et al., 2008).

Many organisms causing mastitis are also hazardous for people. Through pasteurization most of the microorganisms causing diseases among people are eliminated. However, some strains of staphylococcus produce toxins in milk these toxins can resist boiling and drying causing irritation in digestive system together with diarrhea and throwing up. As a result, treatment of mastitis caused by S. aureus is important for wellbeing of both people and animals. Although acute udder infections cause considerable changes in the udders and the milk produced by them, usually no change is observed in the udder or the milk. Since the disease continues unnoticed for a long time and causes considerable loss of milk productivity the most important type of mastitis are subclinical ones (İzgür, 1980).

This study aims at determining prevalence of mastitis cases among the cows located together with isolation and identification of factors causing mastitis and their antibiotic resistance. To this end, the milk determined to have mastitis were identified in terms of the effective bacteria, either S.aureus or E.coli and their antibiotic resistance was determined.

\section{Materials and Methods}

The milk infected by mastitis used in the study were collected from different farms located in the villages of the central district and other districts (Altıntas, Gediz, Tavşanlı) of the province of Kutahya. During the research, first, the milk retrieved from dairy cows was examined using California Mastitis Test (CMT). Next, the milk samples taken from the cows which were found to be CMT positive were analyzed microbiologically and the samples were isolated in terms of active bacteria S.aureus and E.coli. To this end, microbiological analysis was performed on 111 milk samples, collected from cows with mastitis of different stocks and in different periods of lactation. 60 of these samples were isolated as S.aureus and 51 of them as E.coli. The milk samples were taken from the udder lobes in aseptic conditions. As the samples were taken, first the nipples were cleaned with a piece of cotton with $70 \%$ alcohol liquid. Then, the first few squeezes of milk were put away and the following squeezes were put in sterilized tubes with lids in the amount of $10 \mathrm{ml}$ each. Next, the samples were brought to the laboratory in cold chain conditions (Macun et al., 2011). Microbiological analysis of the milk samples was performed in the laboratory.

\section{Staphyococcus aureus isolation}

For S.aureus, first the samples taken were inoculated on blood agar medium and incubated in $37^{\circ} \mathrm{C}$ for 24 hours. After the incubation, the beta-hemolytic colonies were selected to Baird-Parker agar that contain egg yolk tellurite and incubated in $37^{\circ} \mathrm{C}$ for 24 hours. The grey-black colonies and the bright colonies that are surrounded by $2-5 \mathrm{~mm}$ transparent zones (lecithinase positive) were selected and after gram staining the purple coccus clusters were isolated. For identification of the purified isolates; gram staining, catalase test, coagulase test, pigment test, lecithinase test, hemolysis test, urease test, gelatinase test, deoxyribonuclease (DNaz) tests were performed (Gülbandılar, 2006). 


\section{Escherichia coli isolation}

For E.coli isolation, the milk samples were planted on Eosine Methylen Blue (EMB) agar medium and incubated in $37^{\circ} \mathrm{C}$ for 24 hours. After the incubation typical bright metallic colonies with dark greenish centers were isolated and then IMVIC tests were performed for identification (Ünlütürk and Turantas, 2002).

\section{Antibiotic resistance test}

The resistance of the isolates to antibiotics were studied in Mueller Hinton agar (MHA) medium using disk diffusion method (Gülbandılar, 2006). In this study, resistance to penicillin $\mathrm{G}(10 \mu \mathrm{g})$ Erythromycin $(15 \mu \mathrm{g})$, Gentamicin $(10 \mu \mathrm{g})$ Amoxicillin-clavulanic acid (AMC; 20/10 $\mu \mathrm{g})$ was determined. Isolates were first planted on blood agar and incubated in $37^{\circ} \mathrm{C}$ for 24 hours. After the incubation they were taken from fresh culture with a sterile swab and diluted in a tube filled with $1.8 \mathrm{ml}$ isotonic $0.09 \% \mathrm{NaCl}$ solution. They were arranged as for Mc Farland No: $0.5\left(10^{8} \mathrm{cfu} / \mathrm{ml}\right)$ turbidity standard and then were spread inoculated on MHA surface with a swab. Different antibiotic disks were placed onto the surface and then were incubated for one night. The diameter of the inhibition zones were measured the following day. The obtained zone diameters were compared to the zone table of NCCLS (National Commitee for Clinical Laboratory Standarts) and classified as sensitive, semi-sensitive and resistant (Gülbandılar, 2006).

\section{Results}

In our study, 111 milk samples taken from 350 cows were found to be CMT positive and they were microbiologically analyzed. The ratio of subclinical mastitis was determined as $(31.71 \%)$. As a result of microbiological analysis of 111 CMT positive milk samples active bacteria were analyzed in terms of S.aureus and E.coli using traditional biochemical tests and antibiotic susceptibility tests. While 60 of the samples were isolated as $S$. aureus 51 of them were analyzed as E.coli .This study is consistent with similar studies performed in Turkey and abroad. Though clinical examination and CMT procedure realized in Elazig province and some neighboring villages on 1249 cows existence of mastitis was searched for and the result was found to be $60.53 \%$. It was determined that $55.17 \%$ of the cases was subclinical while 5.36\% was clinical mastitis (Rişvanlı and Kalkan 2001). Sabuncuoglu et all., stated that among the cases at Atatürk University Faculty of Agriculture Husbandry Unit, in Erzurum province, the rate of mastitis was determined to be $40 \%$ (Sabuncuoğlu et al., 2003).

In this study, as for the results of antibiotic susceptibility tests for $S$. aureus and E.coli isolates performed with Kirby-Bauer disc diffusion method, for both types of bacteria the highest resistance was found to be against penicillin with 43 (84.31) for E.coli and 45 (75\%) for S.aureus. The antibiotic susceptibility test results reached in the study are given in Table 1.

Table 1. Antibiotic susceptibility results of E.coli ve S.aureus isolates.

\begin{tabular}{|l|c|l|c|c|c|c|}
\hline & \multicolumn{3}{|c|}{ E. coli } & \multicolumn{3}{c|}{ S.aureus } \\
\hline Antibiotic & $\mathrm{S} *(\%)$ & $\mathrm{IS}(\%)$ & $\mathrm{R}(\%)$ & $\mathrm{S} *(\%)$ & ODD $(\%)$ & $\mathrm{R}(\%)$ \\
\hline Penicillin G & $5(9.80)$ & $3(5.88)$ & $43(84.31)$ & $7(11.66)$ & $8(13.33)$ & $45(75)$ \\
\hline Erythromycin & $40(78.43)$ & $6(11.76)$ & $5(9.80)$ & $45(75)$ & $10(16.66)$ & $5(8.33)$ \\
\hline Gentamicin & $35(68.62)$ & $12(23.53)$ & $4(7.84)$ & $32(53.33)$ & $20(33.33)$ & $8(13.33)$ \\
\hline Amoxicillin-clavulanic acid & $37(72.54)$ & $4(7.84)$ & $10(19.60)$ & $43(71.66)$ & $7(11.66)$ & $10(16.66)$ \\
\hline
\end{tabular}

For E.coli isolates the highest susceptibility was against Erythromycin with 40 (78.43\%), and the others were respectively $37(72.54 \%)$ to Amoxicillin -clavulanic acid, 35 (68.62\%) to Gentamicin, and 5 $(9.80 \%)$ to Penicillin G. Moderate susceptibility rates were respectively $12(23.53 \%)$ against Gentamicin,6 (11.76\%) to Erythromycin, $4(7.84 \%)$ to Amoxicillin-clavulanic acid and 3(5.88\%) to Penicillin G.

Among $S$. aureus isolates the highest susceptibility was determined to be against Erythromycin with 45 $(75 \%)$ and the others were respectively; $43(71.66 \%)$ to Amoxicillin-clavulanic acid, $32(53.33 \%)$ to Gentamicin, $7(11.66 \%)$ to Penicillin G. the moderate susceptibility rates were respectively $20(33.33 \%)$ against Gentamicin, $10(16.66 \%)$ to Erythromycin, $8(13.33 \%)$ to Penicillin G and $7(11.66 \%)$ to Amoxicillin-clavulanic acid. This is another similar result with that of the previous studies.

In the studies performed, differences in resistance against the antibiotics to be used for curing the factors 
isolated from subclinical mastitis were determined. Firstly, incorrect treatments applied previously were found to cause formation of these differences and studies revealed that as a result of these treatments resistance against antibiotics was formed (Gülbandılar, 2006).

Chandrasekaran et al., in their study performed in India, determined mast antibiotic resistance in 235 cows among 401, which means $56.1 \%$. The pathogens were determined as $50.64 \%$ E.coli; $44.25 \%$ S.aureus and $5.11 \%$ MRSA. The highest susceptibility was determined to be against respectively enropholoxasin, Amoxicillin + sulbactam, gentamicin and ceftriaxone while the highest resistance was against respectively penicillin, Amoxicillin, oxitetrasiclin and methicillin. Some of the isolates revealed resistance against 1 or 2 antibiotics at the same time while most of the MRSA isolates revealed multiple resistance against 3 or more antibiotics (Chandrasekaran et al., 2014).

Yeşilmen et al., performed a study concerning isolation of factors causing subclinical mastitis among the cows located in Diyarbakır region and isolation and identification of these factors together with determination of the antibiotics effective on them. In their microbiological analysis of 268 milk samples taken from 134 CMT positive cows $29(10.82 \%)$ samples did not produce any bacteria while among 239 (89.18\%) milk samples isolated 66 (24.63\%) Staphylococcus aureus, 30 (11.19\%) Staphylococcus epidermidis, 20 (7.46\%) Staphylococcus haemoliticus, 27 (10.07\%) Streptococcus agalactiae, 10 (3.73\%) Streptococcus dysgalactiae, 5 (1.87\%) Streptococcus uberis, 10 (3.73\%) Bacillus spp., 23 $(8.58 \%)$ Escherichia coli, 10 (3.73\%) Enterobacter cloacae, 10 (3.73\%) Enterobacter faecalis, 5 (1.87\%) Klebsiella pneumonia, 5 (1.87\%) Pseudomonas aeruginosa, 8 (2.99\%) Diplocococus spp., 10 (3.73\%) Candida spp. In the antibiogram test applied against the isolated and identified bacteria the most effective antibiotics were determined to be Cefoperazone-Sulbactam, Cefocitin and ampicillin (Yeşilmen et al., 2012).

A similar study was performed by Dinç et al., on milk samples suspected to have mastitis taken from diary companies located in Ankara, Balıkesir and Çorum provinces. In the antibiotic susceptibility test they applied on $92 \mathrm{E}$. coli strains they isolated from these samples the highest resistance was found against respectively erythromycin $(69.6 \%)$, ampicillin $(39.1 \%)$, tetracycline $(34.8 \%)$, nalidixic acid (25.0\%), chloramphenicol (22.8\%), trimethoprim-sulphametacsazole $(21.7 \%)$ and amoxicillin clavulanic acid $(21.7 \%)$. Besides, they determined that $25.0 \%$ of the strains were susceptible against all the antibiotics used. Moreover, $54.3 \%$ of $E$. coli strains were stated to be resistant against two or more antibiotics in this study (Dinç et al., 2012).

Kalmus, et all., determined that $24.3 \%$ of the E. coli strains that they isolated from the cows with mastitis were resistant against ampicillin, $15.6 \%$ against streptomycin, $13.5 \%$ against tetracycline, $12 \%$ against trimethoprim-sulphometacsazol, 2.2\% against Gentamicin, 1.6\% against enroflocsasin while all the strains were susceptible against sephaperazon. In the same study, in the S.aureus strains they isolated $61.4 \%$ resistance against penicillin was determined (Kalmus et al., 2011).

Idriss et al., performed a study in Slovakia determined 100\% susceptibility against cephtiofur, enropholacsasin and tetradelta in the E.coli strains they isolated while finding 96\%susceptibility against each of the Amoxicillin- clavulanic acid and neomycin antibiotics. The highest resistance was determined to be against cloksasilin with $98 \%$ and the others were respectively $96 \%$ against each of lincomiscin and penicillin, and $82 \%$ against Amoxicillin. Among S.aureus bacteria the highest susceptibility was determined to be against entrophoflaxicine and tetradelta $(97.37 \%)$, the resistance of S.aureus against amoxicillin and streptomycin (18.42\%), lincomycin (3.16\%) and penicillin (10.53\%), respectively ( Idriss et al., 2014)

On the other hand, Muhamed et all., in their study they performed in India have determined that out of $152 \mathrm{~S}$. aureus isolates they have obtained 63 (41.44\%) were resistant against penicillin, 39 (25.65\%) against streptomycin 21(13.81\%) against Erythromycin, 18 (11.84\%) against tetracycline, 6 (3.94\%) against ampicillin and $5(3.28 \%)$ against Cephalothin, while none were resistant against Gentamycin (Muhamed et al., 2012).

A similar study was performed in Jordan. Alekısh et al, in their study that aimed at determining the bacteria that caused mastitis and the resistance of these bacteria to antibiotics have determined that the most extensive distribution was S. aureus (53.4\%), E.coli (16\%), Streptococcus non-agalactiea (Strep non-ag) (5.9\%) and coagulase negative Staphylococcus (CNS) (9\%), respectively. $61.2 \%$ of the isolated pathogen bacteria were susceptible towards enropholacsasin, 58.7\% towards cipropholoksaxin and the highest resistance was towards sulfa/trimethofrim(87.4\%) and (84.5\%) towards penicillin ( Alekısh et al., 2013). 
Hinthong et al., in the work they do resistance to ampicillin, carbenicillin,and sulfamethoxazoletrimethoprim was the pattern found most commonly in the E. coli from milk samples (Hinthong, et al., 2017).

Turkey ranks 3rd among EU countries and 27th in the World in terms of cattle population and the rate of cattle in milk production increases day by day. Nevertheless, in Turkey, as in many other countries, one of the major problems of dairy industry and milker-raising is mastitis. Mastitis is the main animal disease that economically harms dairy industry. The most prevalent pathogens that cause mastitis are S. aureus and $E$. coli bacteria. The identification of the factors that cause the disease is important for taking the disease under control (Atasever and Erdem, 2008) and (Memmedova, 2012).

\section{Discussion}

Since there is no regular registry system regarding this subject in Turkey the prevalence of mastitis and the dimensions of economic loss cannot be precisely known. However, researchers have conducted limited researches that might count as preliminary surveys. With the recent increase in using productive cultivated races in milk production in Turkey mastitis cases have also increased. Especially subclinical mastitis is reported to cause important economic losses. It is also reported that 11 million tons of milk is produced annually however $30 \%$ of the cows have mastitis (Mutluer, 2001).

Although there is a large number of studies concerning isolation, identification and antibiotics resistance conditions of mastitis factors among cows located in different parts of Turkey, any comprehensive studies on this subject applied in the province of Kütahya was not reached. Therefore, it will be possible to take precautions against the losses due to mastitis that take place every year in this province with this study partly. Moreover this study will possibly, inspire further studies aimed at curing this disease.

\section{Acknowledgements}

The financial support for his study was provided by Dumlupinar Universty, Research Projects 2013/30

\section{Conflict of interest}

None of the authors have any conflict of interest to declare.

\section{References}

1. Albenzio, M; Taibi, L; Muscio, A; and Sevi, A (2002). Prevalence and etiology of subclinical mastitis in intensively managed flocs and related changes in the yield and quality of ewe milk. Small Rum Res. 43: 219-226. https://doi.org/10.1016/S0921-4488(02)00022-6

2. Albayrak, AI (2007). Typing of Staphylococcus aureus strains isolated from bovine mastitis with rep-pcr method, Master Thesis. Selcuk University. Institute of Science and Technology. Konya.

3. Baştan, A (2010). Breast health and problems in cows. First Edition. Ankara. 105-134,

4. Bergonier, $\mathbf{D}$ and Bertholet, $\mathbf{X}$ (2003). Newadvances in epizootiology and control of ewe mastitis. Livestock Prod Sci., 79: 1-16. https://doi.org/10.1016/S0301-6226(02)00145-8

5. Alaçam, E; Tekeli, T and Sezen, Y ( 1986). Studies on the effectiveness of Cefoperazone on subclinical mastitis of dairy cows. Veterinary Journal of Selcuk University. 2: 65-74. https://doi.org/10.30607/kvj.579928

6. Sumathi, BR; Amitra, RG and Krishnappa, G (2008). Antibiogram profile based dendogram analysis of Escherichia coli serotypes isolated from bovine mastitis. Vet World. 1: 37-39.

7. İzgür, H (1980). Studies on treatment of subclinical mastitis in cows. Doctoral Thesis. Ankara University Health Sciences Institute. Ankara.

8. Macun, HC; Pir Yağcı, İ; Ünal, N; Kalender, H; Sakarya, F and Yıldırım, M (2011). Agent Isolation and Antibiotic Resistance in Dairy Cows with Subclinical Mastitis in Kırıkkale.J Fac Vet Med Univ Erciyes. 8(2): 83-89. 
9. Gulbandilar, A (2006). Characterization of Staphylococcus aureus isolated from varying sources in Kutahya. Ph. D.Thesis, Anadolu Universty, Institute of Science and Technology. Eskişehir

10. Ünlütürk, A and Turantaş, F (2002). Microbiological Analysis of Foods., İzmir.

11. Rişvanlı, A and Kalkan, C (2001). Distribution of clinical and subclinical mastitis in dairy cows in Elazı ğ region, isolation of microorganisms causing mastitis and a study on susceptibilities of antibiotics. The mastitis symposium in dairy cows. Akdeniz University Veterinary Faculty Publication. 2: 7666-629.

12. Sabuncuoğlu, N; Çolak A; Akbulut, Ö;Tüzemen, N and Bayram, B ( 2003). Relationships between $\mathrm{cmt}$ scores and some milk yield traits in holstein friesian and brown swiss cows, The Journal of Faculty of Veterinary Medicine, University of Atatürk. 34 (2): 139-143.

13. Chandrasekaran, D; Venkatesan, P; Tirumurugaan; KG and Nambi; AP (2014). Thirunavukkarasu PS, Kumanan K, Vairamuthu S, Ramesh,S. Pattern of antibiotic resistant mastitis in dairy cows, Veterinary World. 7(6): 389-394. https://doi:10.14202/vetworld.2014.389-394

14. Yeşilmen, S and Özyurtlu, N; Bademkıran, S (2012). The 1solation of subclinical mastitis agents and determination of the sensitive antibiotics in dairy cows in Diyarbakır province. The Journal of Faculty of Veterinary Medicine, University of Dicle. 1(4): 24-29.

15. Dinç, G; Ata, $\mathbf{Z}$ and Temelli, $\mathbf{S}$ (2012). Investigation of extended-spectrum beta-laktamase activity and antibiotic resistance profile of Escherichia coli strains isolated from bovine mastitis, Veterinary Journal of Ankara University. 59: 85-88.

16. Kalmus, P; Aasmäe, B; Kärssin, A; Orro, T and Kask, K (2011). Udder pathogens and their resistance to antimicrobial agents in dairy cows in Estonia. Acta Vet Scand.53: 1-7. http://www.actavetscand.com/content/53/1/4

17. Idrıss, SE; Foltys, V; Tančın, V; Kırchnerová, K; Tančınová, D and Zaujec, K (2014). .Mastitis pathogens and their resistance against antımicrobial agents in dairy cows in Nıtra, Slovakıa Slovak J. Anim. Sci., 47 (1): 33-38.

18. Muhamed, H.M; Doss, A; Vijayasanthı, $M$ and Venkataswamy, R (2012) Antimicrobial drug susceptibility of Staphylococcus aureus from subclinical bovine mastitis in Coimbatore, Tamilnadu, South India, Veterinary World. 5 (6): 352-355. https://doi:10.5455/vetworld.2012.352-355

19. Alekısh, MO, Al-Qudah, KM and Al-Saleh, A (2013). Prevalence of antimicrobial resistance among bacterial pathogens isolated from bovine mastitis in northern Jordan. Revue Méd. Vét., 164(6): 319-326.

20. Hinthong, W; Pumipuntu, N; Santajit, S; Kulpeanprasit, S; Buranasinsup, S; Sookrung, N; Chaicumpa, W; Aiumurai, P and Indrawattana, N (2017). Detection and drug resistance profile of Escherichiacoli from subclinical mastitis cows and water supply in dairy farms in Saraburi Province, Thailand. PeerJ., 3431:1-16 https://doi.org/10.7717/peerj.3431

21. Atasever, S and Erdem, H (2008). Relationships between mastitis and electrical conductivity of raw milk in darry cows J. of Fac. Of Agric., 23(2): 131-136. 